\title{
How should we define, document, and prevent conflicts of interest in alcohol research?
}

\author{
Thomas F. Babor ${ }^{1}$ \\ ${ }^{1}$ University of Connecticut School of Medicine, Farmington, CT, United States
}

\begin{abstract}
Aims: Conflicts of interest (COIs), in science and medicine, have come under increasing scrutiny in recent years. This article reviews definitions of COI, as well as measures used to document, prevent, and manage COIs.

Findings: The positive association between COIs and the outcomes of research has been documented in a substantial body of research covering a variety of fields, including addiction research. Attempts to address COIs include funding declarations, voluntary bans of receipt of industry funding, and ethical analyses.

Conclusions: To protect the scientific integrity of the alcohol field from further influence from commercial and other competing interests, reasonable and consistent reporting procedures are needed at a minimum. Direct funding from major transnational alcohol producers involves major reputational and ethical risks that may require more stringent measures by professional societies, university administrators, and journal editors.
\end{abstract}

Conflicts of interest (COIs) in medicine and addiction science have come under increasing scrutiny in recent years (Babor, 2009a, b; Babor \& Miller, 2014). Failures to disclose COIs have become a major embarrassment to publishers, editors, and professional societies. The positive association between COIs and the outcomes of research has been documented in a substantial body of research covering a variety of fields (Bekelman, Li, \& Gross, 2003; Yank, Rennie, \& Bero, 2007). Industry funding increases the likelihood that researchers will produce pro-industry results, publish biased interpretations of trial results, and even suppress the publication of negative findings (see Miller, Babor, McGovern, Obot, \& Buhringher [2008] for a review of this literature as it pertains to addiction research). Virtually all of this research has focused on financial COIs, in part because these conflicts are easier to report and to document. This article reviews definitions of COI, measures used to document COIs, and procedures developed to prevent and manage COIs.

A conflict of interest is a situation or relationship in which professional, personal, or financial considerations could be seen by a fair-minded person as potentially in conflict with independence of judgement (Farmington Consensus, 1997). A conflict may be personal, commercial, political, academic, or financial. Personal conflicts include favoritism toward theories or findings validating one's own ideas and strong friendships or hostile relationships between individuals. Financial interests may include employment, research funding, stock or share ownership, payment for lectures or travel, consultancies, and company support for staff. COIs are not in themselves wrongdoing, but they create serious problems within the field of addiction science.

The potential for financial COIs in the alcohol field is enhanced by relationships or funding connected with the alcohol beverage industry, for-profit healthcare systems, private hospitals, the pharmaceutical industry, and "social aspect organizations" that receive their primary support from these sources (Babor, 2009a; Babor \& Miller, 2014). Government funding agencies may also present the potential for COI, as when a funding source applies direct or indirect pressure to achieve a particular research outcome. They can do this by selecting the types of research funded and by subtle or outright censorship of scientific findings.

There are three levels of COI. A real COI means that a scientist or a scientific author has a financial or other interest that could unduly influence the person's behavior with respect to the subject matter being considered. An apparent COI exists when an interest would not necessarily influence the author but could result in the author's objectivity being questioned by others. A potential COI exists when a reasonable person might be uncertain as to whether or not an interest should be reported or managed.

Correspondence: Thomas F. Babor, Ph.D., MPH, Professor and Chairman, Dept. of Community Medicine \& Health Care, University of Connecticut School of Medicine, 263 Farmington Avenue, Farmington, CT 06030-6325. Telephone: (860) 679-5481; Fax: (860) 679-5463; E-mail: babor@uchc.edu Financial support: This research was supported by NIH/NIAAA 5P60AA003510-38.

Keywords: conflict of interest, alcohol, research bias, research integrity, alcohol 
Other forms of COI that are relevant to the alcohol research field include efforts by commercial interests to control the scientific agenda and interpretation of research findings in order to promote or protect their profits. By accepting funding from industry sources and industry-supported organizations, addiction scientists may unwittingly give credibility and power to vested interests that are providing funding to protect or enhance their own business, often at the expense of public health. The findings from social science and neuroscience suggest that COIs may be a result of unintentional bias rather than intentional dishonesty (Cain \& Detsky, 2008).

Many of the COIs defined above are difficult to document. Attempts to address COIs have been based primarily on the assumption that the declaration of relevant information about personal and financial relationships, when provided accurately to editors, reviewers, and consumers of scientific research, is the minimum requirement for the documentation of real, apparent, and potential COIs. Personal biases, especially when they are against other individuals, require very subjective judgments and may be difficult to state publically. Financial relationships are easier to document but opinions differ as to what should be declared (Goozner et al., 2009). One difficulty with documentation of COIs is the lack of transparency on the part of some funding sources, where the real nature of the industry funding may be hidden, as it was in the case of the tobacco industry setting up a research funding institute to protect its financial interests (Hirshhorn, Aguinaga-Bialous, \& Shatenstein, 2001; King, 2006).

The use of consistent and transparent declaration policies by journal editors is the method of choice to address COIs. But in response to threats to the integrity of science, scientific journals, professional organizations, and other institutions have attempted to go beyond COI declaration policies. The solutions range from outright bans on the acceptance of industry funding to more modest efforts to increase transparency and educate stakeholders. In 2008, a group of academics and nongovernmental organization representatives issued The CLARION Declaration, which encouraged scientists and nongovernmental organizations to refrain from accepting funding from the alcohol industry. In 2015, INEBRIA, a small professional association devoted to alcohol screening and brief intervention research, issued a Position Statement discouraging its members from seeking or receiving funding from the alcohol industry, including such research funding bodies as The Foundation for Alcohol Research and The European Foundation for Alcohol Research. Although membership in INEBRIA will not be contingent on non-receipt of funds from the alcohol industry, all current members and individuals wishing to join INEBRIA will be invited to endorse this position statement.

Another prevention measure is to ask researchers to conduct a PERIL Analysis (Adams, 2007), which is an ethical decision-making framework that takes into account the conflicting purposes of the industry providing funding and the recipient, the extent of the support, the relevant harm to society, the degree of identification between the funder and the recipient, and the nature of the link (direct or indirect) between the two. The overall extent of moral jeopardy ranges from very high levels, as indicated by high ratings on all five dimensions, to very low levels. Decisions regarding future industry relationships are made accordingly.

The evidence for COIs posing potential damage to the integrity of science is clear and compelling. At present there is no consensus in the alcohol field about whether or not a scientist should accept funding from these kinds of vested interests. Nevertheless, concern about COI issues has resulted in a set of inconsistent policies, procedures, and precedents. To protect the scientific integrity of the alcohol field from further influence from commercial and other competing interests, reasonable and consistent reporting procedures are needed at a minimum. Receipt of direct funding from major transnational alcohol producers involves major reputational and ethical risks that may require more stringent measures by professional societies, university administrators, and journal editors. What is becoming increasingly apparent is that research bias is not the only issue of concern. Other consequences of COIs include dissention among colleagues, agenda setting by commercial interests, increased bureaucratic regulation, and the use of research funding by commercial interests to purchase undeserved legitimacy.

\section{References}

Adams, P. J. (2007). Assessing whether to receive funding support from tobacco, alcohol, gambling and other dangerous consumption industries. Addiction, 102, 1027-1033.

Babor, T. F. (2009a). Alcohol research and the alcoholic beverage industry: Issues, concerns and conflicts of interest. Addiction, 104, 34-47.

Babor, T. F. (2009b). Towards a common standard for conflict of interest disclosure. Addiction, 104, 17771778.

Babor, T. F., \& Miller, P. (2014). McCarthyism, conflict of interest and Addiction's new transparency declaration procedures. Addiction, 109, 341-344. [Corrigendum 109, 1389].

Bekelman, J. E., Li, Y., \& Gross, C. P. (2003). Scope and impact of financial conflicts of interest in biomedical research: A systematic review. JAMA, 289(4), 454465.

Cain, D. M. \& Detsky, D. S. (2008) Everyone's a little bit biased (even physicians). JAMA, 299(24), 2893-2895. doi:10.1001/jama.299.24.2893

CLARION Declaration. (2008). Nordic Studies on Alcohol and Drugs, 25, 316.

Farmington Consensus. (1997). Addiction, 92, 1617-1618.

INEBRIA. (2015). Position statement on the alcohol industry. Retrieved from http://www.inebria.net/Du14/ pdf/position_statement_on_the_alcohol_industry.pdf

Goozner, M., Caplan, A., Moreno, J., Kramer, B. S., Babor, T. F., \& Husser, W. C. (2009). A common standard for conflict of interest disclosure in addiction journals. Addiction, 104, 1779-1784. 
Hirshhorn, N., Aguinaga-Bialous, S., \& Shatenstein, S. (2001). Philip Morris' new scientific initiative: An analysis. Tobacco Control, 10, 247-252.

King, J. (2006). Accepting tobacco industry money for research: Has anything changed now that harm reduction is on the agenda? Addiction, 101(8), 10671069.

Miller, P., Babor, T. F., McGovern, T., Obot, I., \& Buhringher, G. (2008). Relationships with the alcoholic beverage industry, pharmaceutical companies and other funding agencies: Holy Grail or poisoned chalice? In T. F. Babor, K. Stenius, S. Savva, \& J. O’Reilly (Eds.), Publishing addiction science: A guide for the perplexed (2nd ed., pp. 190-212). London, England: Multi-Science Publishing Company.

Yank, V., Rennie, D., \& Bero, L. A. (2007). Financial ties and concordance between results and conclusions in meta-analyses: Retrospective cohort study. BMJ, 335(7631), 1202-1205. 